\title{
Study on Internal Factors Influencing Chinese College Students' Willingness to Communicate in English Based on Logistic Regression Analysis Model
}

\author{
Yunda Yang ${ }^{\mathrm{a}}$ and Weiping $\mathrm{Wu}^{\mathrm{b}}$ \\ School of Foreign Languages, Wuhan University of Technology, Wuhan 430070, China \\ ayunda21@126.com, bweipingw@163.com
}

\begin{abstract}
Keywords: willingness to communicate, internal factors, logistic regression model, qualitative and quantitative.
\end{abstract}

\begin{abstract}
Willingness to communicate (WTC) is an essential concept in research fields of second language acquisition (SLA) and second language communication. In recent years, related researches in China have made great achievements. Based on relevant theories, the article enlarges research subjects of WTC to Chinese college students, and explore the relationship between WTC and internal factors. The research crunches the data by qualitative and quantitative methods. Moreover, the research uses SPSS 20.0, a kind of analysis tool, to establish logistic regression model and verify the correlation between WTC and internal factors which may affect Chinese college students' WTC.
\end{abstract}

\section{Introduction}

With the spreading application of communicative teaching method, cultivating the ability of English communication has become a primary target. Meanwhile further developments of economic globalization facilitate the society to raise higher demands for talents with English competence.

Education Administration of China has proposed that the teaching of college English aims to cultivate students to have comprehensive applying competence, especially listening and speaking ability. This action is to make sure that graduate students could communicate efficiently through oral and literal information in later work and social communication.

Related researches had proved that Silence Phenomenon of Chinese students in foreign language classes is common and these students have less willingness to communicate in English (Kennedy, 2002). Generally the scholars agree that any teaching ways of foreign language, which could not inspire students' willingness to communicate in that language, is a failure. As a result, the first step of truly improving learners' oral ability is to cultivate their communicative willingness to communicate in foreign language. (Wu, 2008)

The article is to analyze the statistics based on logistic model and explore the connection among willingness to communicate and individually inner elements. The aim is to enlighten educationists to apply more scientific teaching methods in cultivating students' oral English.

\section{Literature Review}

McCroskey and Richmond put forward the concept of Willingness to communicate (WTC) in 1985 - the tendency of an individual to initiate communication when free to do so, to explain differences of regular languages and behaviors in mother tongue communication among individuals. The research on individual differences of second language acquisition illustrated that mental elements could influence the states of second language acquisition, including attitudes, motivations and anxiety etc.

Gardner and Lambert (1985) proposed a social education model of second language acquisition and pointed out that three major components of learning language - attitudes towards language and culture, desire for language learning, motivation intensity. Macintyre (1994) set up a model of the communicative willingness of mother tongue about communicative fear and anxieties affecting communicative behaviors. Later, Macintyre applied this model to second language communication. In 1998, Macintyre, Clement, Dörnyei and Noels proposed a layered pyramid model of 
communicative willingness of second language, which extended the study of communicative willingness to the field of second language acquisition, and elaborated the complexity of WTC in second language learning, which was a more comprehensive explanation of factors affecting the WTC. In this model, the communicative willingness of second language is defined as, at a given moment, the individual initiates the willingness to communicate with other subjects in the second language (Macintyre et al, 1998). Dörnyei (2005) thought that the communicative willingness is a collection of individual differences variables, including a series of learner variables, which may have an impact on second language acquisition and application. Macintyre (2007) argued that communicative willingness is a method of second language research, integrating psychology, linguistic, education, and communication. Being a brand-new research direction in applied linguistics and second language acquisition, WTC has aroused great interests in academia and had a great influence on language teaching.

Compared with the study in foreign countries, the study of WTC in China is still in the infancy, and the researches on WTC by multivariate statistics and effective statistical methods are rare. So far, Chinese scholars have made such researches: the influence of Chinese traditional society culture on WTC of Chinese students and learning methods (Wen, Clément, 2003; Peng, 2006; Zhang, 2016); the affection of Study motivation, individual characters and communicative environment on WTC of Chinese college students excluding English major (Chen, 2006; Kong, 2016); evaluation on the degrees of college students' WTC in specific areas (Asker, 1998); exploration on the relation among study motivation, attitude and college students' WTC (Chen, 2014; Lu,2015; Wang,2016); comprehensive analysis and statement on WTC in recent 20 years (Yin, 20; Peng, 20); establishing the WTC forming model on college students by mathematical analysis (Wu, 2006; Xie, Guo, 2011). Above researches setting Chinese English learners as research subject contribute the development of related research of WTC in China and have a certain reference value.

\section{Research Design}

\subsection{Research Subject.}

The sample of this study is derived from 400 college students (covering first-class universities, second-class universities and some institutes and colleges) from one to four grades across the country. The students come respectively from majors including journalism, management, economy, law, materials, automation, computer science, etc. The proportion of subjects is as follows: English $18.73 \%$, arts except English 20.76\%, science and engineering 31.14\%, other subjects accounting for $29.37 \%$.

\subsection{Research Methods.}

\subsubsection{Qualitative Research.}

According to WTC, the author designs 10 open questions as interview contents and selects randomly 6 college students from different majors as interview subjects. In order to create relaxed atmosphere for interview, the author uses the form of chatting during the interview. The interview lasts for nearly one hour.

\subsubsection{Quantitative Research.}

The questionnaire is based on the model of the willingness of bilingual communication constructed in 1998 by Macintyre. This model is represented as the pyramid form stratified according to different interaction degrees among variables. On the basis of interviews of 6 students for the elements which influence the willingness of English communication, the author collates and designs the questionnaire concerning the internal factors which may affect the intention of English communication of Chinese college students. Then the author localizes the questionnaire to make it more scientific, subjective and real.

The questionnaire includes two parts. One is students' personal information, including locations of universities, majors, grades and scores of CET 4; the other is the scale of the internal factors including 7 factors that may influence college students' WTC in English. (Confidence, frequency, motivation, attention, anxiety, interest, competence). 


\subsection{Data Acquisition.}

400 questionnaires are distributed and reclaimed in September 2016 by e-mails and internet questionnaires. Among all questionnaires, 395 are effective, $98.75 \%$ of the ensemble; 5 are invalid, accounting for $2.15 \%$. The data of questionnaires are analyzed by SPSS 20 . Firstly, the authors carries on the diagnosis of multicollinearity to determine that the multicollinearity does not exist among the variables; then, tests the model's fitness degree of the data to ensure that independent variables can predict the dependent variable accurately; at last, uses logistic binary regression model to verify and analyze individual factors which may affect Chinese college students' WTC in English.

\subsection{Choice of Model.}

Logistic model, a model first derived from the Belgian mathematician Verhulst (1804-1849), has applied extensively in many fields like social investigation, medical research and biological information processing for its efficiency.

As a nonlinear classification statistical method, logistic regression model provides results in the form of event occurrence rate and it has been widely used in the analysis of influencing factors. Logistic regression model is recognized as a common method applied in study of relationship among dependent variables and independent variables.

The concrete form of logistic model is as below:

$$
\begin{aligned}
& p=\frac{e^{f(x)}}{1+e^{f(x)}} \\
& 1-p=\frac{e^{f(x)}}{1+e^{f(x)}}
\end{aligned}
$$

Logarithmic transformation:

$$
\ln \left[\frac{P}{1-p}\right]=f(x)=\alpha+\beta_{1} x_{1}+\beta_{2} x_{2}+\cdots+\beta_{i} x_{i}+\varepsilon
$$

$\mathrm{P}$ is the probability of students willing to communicate in English and 1-p is the probability of students unwilling to communicate in English; $x_{i}$ is explanatory variables ; $\beta_{i}$ is the $i$ th influence coefficient; $\alpha$ is constant term; $\varepsilon$ is error.

\section{Results}

\subsection{Description of Independent Variables.}

Seven internal factors influencing college students' willingness to communicate in English are taken the measurement of Likert Five-point Scale, each answer is given the corresponding score, and assigned 5, 4, 3, 2, 1 in turn according to different degrees of strength. Variable interpretation, variable assignment and description are in Table 1.

\subsection{Analysis on multicollinearity.}

The research selects seven variables to reflect the individual factors influencing college students' communicative intention. Due to the large number of variables, there may exist the collinearity among the variables. The study by Hanushek and Jackson proved that parametric estimates of common logistic regression models are easily affected by collinearity among explanatory variables. Colinearity test of each variable can reduce the influence of collinearity of variables.

The research uses SPSS 20.0 software to measure the covariance of independent variables by variance inflation factors (VIF). The results are in Table 2. It is generally believed that variance inflation factor $(\mathrm{VIF}) \geq 5$, which means there exists multicollinearity among independent variables. In Table 2, VIF maximum value equals 1.889 , less than 5, which determines that explanatory variables are not of multicollinearity, thus there is no need removing and integrating these variables, and the research can maintain seven independent variables for further analysis. 
Table 1 Analysis and Description of Independent Variables

\begin{tabular}{|c|c|c|c|c|c|c|c|}
\hline $\begin{array}{c}\text { Type of } \\
\text { Variables }\end{array}$ & $\begin{array}{l}\text { Name of } \\
\text { Variables }\end{array}$ & $\begin{array}{l}\text { Description } \\
\text { of Variables }\end{array}$ & $\underset{\mathrm{m}}{\text { Minimu }}$ & $\begin{array}{c}\text { Maximu } \\
\mathrm{m}\end{array}$ & $\begin{array}{c}\text { Mea } \\
\text { n } \\
\text { Valu } \\
\text { e }\end{array}$ & $\begin{array}{c}\text { Standard } \\
\text { Deviatio } \\
\mathrm{n}\end{array}$ & $\begin{array}{c}\text { Expected } \\
\text { Orientatio } \\
n\end{array}$ \\
\hline $\begin{array}{l}\text { Dependent } \\
\text { Variable }\end{array}$ & $\begin{array}{c}\text { Willingnes } \\
\mathrm{s}\end{array}$ & $\mathrm{Yes}=1 ; \mathrm{No}=0$ & 0 & 1 & 0.71 & 0.454 & \\
\hline \multirow{7}{*}{$\begin{array}{l}\text { Independen } \\
\text { t Variable }\end{array}$} & Confidence & \multirow{6}{*}{$\begin{array}{c}\text { Stronger }=5 ; \\
\text { Strong=4; } \\
\text { Average=3; } \\
\text { Weak=2; } \\
\text { Weaker }=1\end{array}$} & 1 & 5 & 2.40 & 1.028 & + \\
\hline & Frequency & & 1 & 5 & 2.43 & 0.853 & + \\
\hline & Attention & & 1 & 5 & 4.50 & 0.749 & + \\
\hline & Motivation & & 1 & 5 & 4.01 & 0.991 & + \\
\hline & Anxiety & & 1 & 5 & 3.10 & 0.952 & - \\
\hline & Interest & & 1 & 5 & 3.98 & 0.956 & + \\
\hline & $\begin{array}{c}\text { Competenc } \\
\mathrm{e}\end{array}$ & 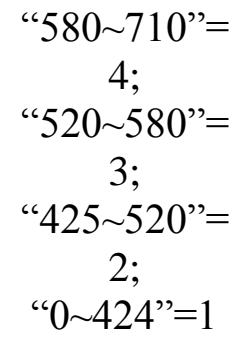 & 1 & 4 & 2.52 & 0.906 & + \\
\hline
\end{tabular}

Table 2 Diagnosis on Multicollinearity of Explanatory Variables

\begin{tabular}{cc}
\hline Independent Variables & VIF \\
\hline x1(Confidence) & 1.679 \\
x2(Frequency) & 1.644 \\
x3(Attention) & 1.815 \\
x4(Motivation) & 1.889 \\
x5(Anxiety) & 1.266 \\
x6(Interest) & 1.142 \\
x7(Competence) & 1.201
\end{tabular}

\subsection{Test of Fitting Degree.}

To testify whether the established model could be used to analyze the data, the author verifies the significance and fitness of overall model coefficients. The study chooses two kinds of verification methods- Omnibus and Hosmer and Lemeshow (H-L), to test the fitting degree of logistic regression model.

\subsubsection{Verification of Significance.}

Verification of Significance shows that Chi-square value which could verify the fitness degree of overall regression model established by seven variables equals $79.799, \mathrm{p}=0.000<0.05$, which reaches the degree of significance. The result proves that at least one variable among seven variables could efficiently explains and estimates models' classification results of Chinese students' WTC in English.

\subsubsection{Verification of Fitness.}

Provided that $\mathrm{H}-\mathrm{L}$ testing value could not reach the degree of significance, it means that fitness of model is appropriate. The fitness-verifying result of regression model by Hosmer and Lemeshow shows that H-L value is 15.507 , not reaching the degree of significance. It proves that the fitness of model is good, that's to say, independent variables can efficiently estimate dependent variables.

Verifications of Omnibus and Hosmer and Lemeshow show that the fitting degree of logistic model is efficient, which means that the regression efforts can reflect Chinese students' WTC in English. 


\subsection{Results of Regression Model.}

Use SPSS 20.0 Software to carry on Logistic Regression and choose "output" as the regression method. The regression results are in Table 3.

Table 3 Results of Regression Model

\begin{tabular}{ccccccccc}
\hline Variables & \multirow{2}{*}{$\mathbf{B}$} & S.E, & Wals & df & \multirow{2}{*}{ Sig. } & \multirow{2}{*}{$\boldsymbol{E x p}(\mathbf{B})$} & \multicolumn{2}{c}{ 95\% C.I. of $\operatorname{Exp}(\mathbf{B})$} \\
& & & & & & & Min & Max \\
\hline $\mathbf{x 1}$ & $0.522^{* *}$ & 0.222 & 5.552 & 1 & 0.018 & 1.686 & 1.092 & 2.604 \\
\hline $\mathbf{x 2}$ & $0.659^{* *}$ & 0.304 & 4.703 & 1 & 0.030 & 1.934 & 1.065 & 3.509 \\
\hline $\mathbf{x 3}$ & $0.590^{* *}$ & 0.294 & 4.024 & 1 & 0.045 & 1.805 & 1.014 & 3.213 \\
\hline $\mathbf{x 4}$ & $0.542^{* *}$ & 0.227 & 5.713 & 1 & 0.017 & 1.720 & 1.103 & 2.683 \\
\hline $\mathbf{x 5}$ & -0.159 & 0.185 & 0.734 & 1 & 0.392 & 0.853 & 0.593 & 1.227 \\
\hline $\mathbf{x 6}$ & 0.269 & 0.182 & 2.189 & 1 & 0.139 & 1.308 & 0.916 & 1.868 \\
\hline $\mathbf{x 7}$ & 0.145 & 0.184 & 0.626 & 1 & 0.429 & 1.156 & 0.807 & 1.657 \\
\hline
\end{tabular}

(1) In Procedure 1, $\mathrm{x} 1=$ Confidence, $\mathrm{x} 2=$ Frequency, $\mathrm{x} 3=$ Attention, $\mathrm{x} 4=$ Motivation, $\mathrm{x} 5=$ Anxiety, $\mathrm{x} 6=$ Interest, $\mathrm{x} 7=$ Competence; (2) $* * *, * * *$ represent the degree of significance $10 \%, 5 \%$, $1 \%$.Discussion.

\subsection{Analysis on Individual Factors.}

\subsubsection{Confidence.}

Confidence in second language is positively correlated with college students' WTC in English. Students who are more confident in the assessment of EFL competence have higher willingness in English communication.

Confidence in foreign language is a complex factor with a strong stability and have correlations with other individual factors such as competence of foreign language, self-characters, degree of anxiety and family background.

Confidence is produced during the mental process when people try using their limited experience to learn about new knowledge, in other words, individual could evaluate their own ability of succeeding in handling the specific environment (Self-efficacy theory, Bandura). In essence, confidence is a kind of enthusiasm and positive attitude to self-evaluation. People with confidence in their foreign language may control the whole communicating process, for example, they can present a sense of control or elastic flexibility in communicative topics, response and output of language, or communication orders and benign maintain. They could adjust themselves more properly and maintain communication better.

During the process of communication, people can think and respond by language information. It is transparent to find the essential function of language confidence in the communication because language assists people or limits them in description and analysis of communication topic. Confidence in foreign language can not only help communicators have a good state, but also promote them express true meanings which can reflect their thoughts and spirits. All mentioned could maintain the benign interaction

In conclusion, college students who are more confident about their oral English ability can gain the demand of mood and convey their meanings of minds by English communication, so they could show greater willingness to communicate.

\subsubsection{Frequency.}

The frequency of communication is positively correlated with college students' WTC in English. The more frequent English communication, the higher the willingness of English communication.

To some extent, the frequency of English communication can reflect the college students' habits of English communication. During the conversation, we find that students who have the higher frequency of communicating in English use less time in the whole course of English listening input, reaction of two languages and oral feedback, which shows that they have a better adaptability in switching two languages when they use them. When students use two languages in the environment of mother tongue in the communication, if their adaptability of using two languages is not good, it is difficult for them to enter the condition of communicating well, but also turn to be anxious and have an inimical attitude towards the conversation. 
According to influence of language habits on communication, oral English, which Chinese students use in the conversation, is most relatively simple communicative language they can blurt out and spend less time in transforming their thinking into language expression. That shows that students are very familiar with these communicative languages and can master them flexibly and skillfully. Communicative languages are largely determined by the accumulation and application in English conversation.

\subsubsection{Attention and Communicative Motivation.}

Degree of attention is positively correlated with college students' WTC in English. The higher the attention degree of English communication, the higher the willingness to communication in English.

Communicative motivation is positively correlated with college students' WTC in English. The stronger the motivation of English communication is, the higher the willingness to communication in English is. Communication motivation and degree of attention have similarity and commonality, so the author puts both together to analyze.

Motivation is a kind of process of internal states, which guides individually conscious behaviors with energy and impulse of the specific purpose. Moreover, it could maintain this behavior. Motivation could be divided into two categories, integrative motivation and instrumental motivation.

Integrative motivation is invisible and spontaneous, and usually presents an interest-driven state, while instrumental motivation is visible with a strong utilitarian and purpose, usually to meet the need of reality. Through conversation, we find that communicative motivations of college students WTC in English are diverse, such as affection and interest in English, demands of personal development, pressure of oral examinations. Among them, the number of students whose motivation is demands of personal development, accounts for a larger proportion. Students with interpersonal motivations have similar experiences of practicing spoken English, like joining in English clubs or English corners, which also reflects attention degrees of students who are willing to communicate in English are higher. The degree of attention can stimulate students' willingness to grasp the opportunities of English communication and inspire students' inner driving force and execution force in English communication.

\subsubsection{Anxiety.}

Degree of Anxiety when speaking English is negatively correlated with college students' WTC in English. The more anxiety of foreign language students, the lower the communicative willingness of college students to communicate in English.

According to previous researches, both communication willingness in the second language and that in mother tongue can be affected by the degree of anxiety. Anxiety and psychological tension of the speaker would be influential not only on his/ her comprehension and information input from other speakers, but also on language structure and output of his/ her own words in communication.

Anxiety arouse from foreign language depends partly on the confidence in using them, namely the unassured feeling in interpersonal skills and language competence. College students tend to feel emotionally anxious in the process of "mother tongue to English" translation. Due to the lack of language environment, delayed responses in language organization, frequent pauses, grammatical mistakes or improper diction may trouble them. What Chinese college students fear is embarrassing situation where they feel ashamed of mistakes they've made, thus the more prone to foreign language anxiety, the less willingness for college students to communicate in English.

\subsubsection{Interest.}

The interest which students show to topics is directly proportional to their willingness in English communication. The more interested they're in topics, the stronger their willingness would be in English communication.

Interest is based on the sense of demand so that when people feel needed of something or activities appeal to them, they would become keen to get familiar or know more about activities of this sort. Therefore they may try to involve themselves in activities. Based on previous studies, this concept is also applicable in the study of WTC in English.

There are mainly two kinds of communication interests here we refer to: direct interest and indirect interest. The former one signifies the interest in communication topics or patterns, and the sense of 
participation developing in English interaction; the latter one deals with what one expects from communication and his/ her curiosity. Both can motivate undergraduates to take part in discussion and interaction. Those showing direct interest in English interaction are more apt to express their own opinions on the topics of their interest because they are inclined to share what they know with others. For indirect interest, their willingness in communication would become increasingly strong with the proceeding of interaction, which is driven by their expectations and eagerness to explore such kind of topics.

\subsubsection{Competence.}

According to the model result, the coefficient is 0.120, which means that English competence is positively correlated with college students' WTC in English, correspondent with the previous expectation. However, the deviation is 0.513 , which indicates that the relationship between English competence and college students' WTC in English is not significant.

The ability of language structure and writing has no obvious connection with verbal expression of language. In other words, the difference between the competence of literal language and the ability of language expression is not clear. In particular, traditional patterns of foreign language teaching in our country cause serious imbalance between competence of testing literal English and training of oral English training. It also proves that the correlation between the English proficiency and WTC in English is not significant.

\subsection{Scale of Internal Factors.}

Then we analyze the principal components of above factors and find that the degree percentage of four major factors (confidence of foreign language, frequency of speaking English, attention, and Communicative motivation) reaches $80.343 \%$.

Therefore we can assume that confidence of foreign language, frequency of speaking English, attention and communicative motivation are main internal factors. According to the results of the above research, the scale of internal factors influencing Chinese students' WTC in English is as below:

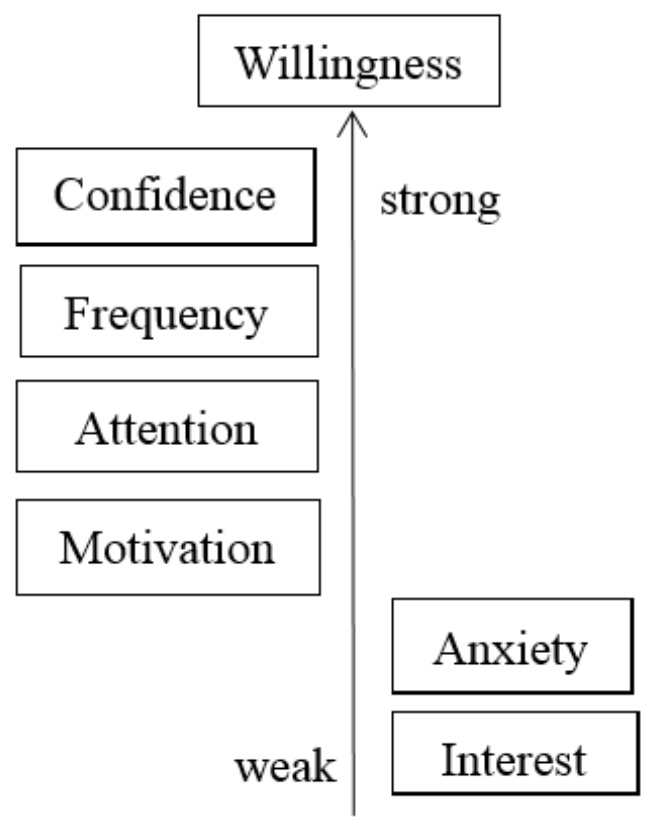

\section{Correlation}

Fig. 1 Scale of internal factors influencing Chinese college students' WTC in English

\subsection{Suggestions on Teaching.}

Speaking more is an efficient way to improve the ability of oral English. In class, teachers try their best to accomplish teaching tasks in English to form English-speaking environment and inspire students to speak English. After class, teachers may organize some communicative activities like holding an English corner, joining in English club, inviting foreign students to deliver lectures about life and study, to provide chances of speaking English for students. 
Besides, teachers could organize a lecture about choosing vocations and studying aboard, invite few experienced upperclassmen to make conversations, share stories and news aboard, watch some beneficial videos and recommend English books and magazines, to broaden students' horizons and foster their interests and attentions about English. Furthermore, teachers may communicate with students after class and watch their implications about what is popular among them, what they focus on, what may cause their interests and activeness. Meanwhile, communicative topics at class should fit interests of major students. Besides, teachers can try diverse types of communication, like discussion, debate or Question and Answer one by one instead of traditionally stable communicative patterns, to enrich the class content.

Teachers should arouse students' WTC and use presentation, performance or speech to offer opportunities of showing themselves to students. Moreover, encourage students to speak more and rise them up by some incentive word Conclusion

At present, domestic and international researches on WTC in English lack empirical data and statistical experience. This research is combined with the current situation of Chinese college students by qualitative and quantitative research methods, and uses logistic regression model as the statistical tool, which is universally accepted by international statistical circles. The article has great significance for the study of Chinese college students' WTC in English.

According to the actual situation of Chinese college students' English communication, previous research results are improved and localized to measure the actual situation of internal factors affecting Chinese college students' WTC in English. Besides the article can help college students to understand their own degree of English communication willingness better and arouse their attention and selfawareness of English communication ability. At the same time, it can also provide some references and suggestions on how to improve students' communicative willingness in English teaching effectively.

However, the study just analyzes internal factors that may influence Chinese college students' WTC in English. It is necessary to proceed further study and analysis on the possibly external factors, such as language environment, communicative pattern and communicative subjects.

\section{References}

[1]. Asker, B. Student reticence and oral testing: A Hong Kong study of willingness to communicate [J]. Communication Research Reports. Vol. 15 (1998) No. 2, p. 162-169.

[2]. Baker, S. C., \&Macintyre, P. D. The role of gender and immersion in communication and second language acquisition [J]. Language Learning. Vol. 53 (2003) No. S1, p. 65-96.

[3]. . Gardner, R. C. Social Psychology and Second Language Learning: The Role of Attitudes and Motivation [M]. Mahwah, NJ: Lawrence Erlbaum Associates. 2001.

[4]. Jiang Hongwei, Zhang Luoman, Meng Hong. A Stimulation Study on Comparison between Three Dimension-reduced Methods for Colinearity in Logistic Regression Models [J]. Chinese Journal of Health Statistic. Vol. 27 (2010) No. 6, p. 562-566.

[5]. Kennedy, K. Learning cultures and learning styles: Myth-understandings of adult (Hong Kong) Chinese learners [J]. International Journal of Lifelong Education. Vol. 21 (2010) No. 5, p. 430445.

[6]. Li Lin. Non-English-Majors' WTC in the Classroom and Enlightenment on Teaching [J]. English Square Academic Research. 2012. No. 8, p. 67-68.

[7]. Liu Qijun, Zeng Qing. Logistic Regression Model and Research Development [J]. Journal of Preventive Medicine Information. Vol. 18 (2002) No. 5, p. 417-419.

[8]. Macintyre, P. D., Baker, S. C., Clément, R., \& Donovan, L.A. Sex and age effects on willingness to communicate, anxiety, perceived competence, and L2 motivation among junior high school French immersion students [J]. Language Leaning. Vol. 53 (2002) No. 3, p. 537-564.

[9]. Macintyre, P. D., \&Charos, C. Personality, attitudes, and affect as predictors of second language communication [J]. Journal of Language and Social Psychology. Vol. 15 (1996) No. 1, p. 3-26. 
[10]. Macintyre, P. D., Clément, R., Dörnyei, Z., \& Noels, K. A. Conceptualizing willingness to communicate in a L2: A situational model of L2 confidence and affiliation [J]. The Modern Language Journal. Vol. 82 (1998) No. 4, p. 545-562.

[11]. McCroskey, J. C., \& Baer, J. E. Willingness to communicate: The construct and its measurement $[R]$. Paper presented at the annual convention of the Speech Communication Association, Denver, Colorado. 1985.

[12]. . Peng Jiane. Multivariate Research of College Students' Willingness to Communicate in English [J]. Foreign Language and Literature Studies. Vol. 24 (2007) No. 4, p. 260-265.

[13]. Shi Chaojian, Zhang Mingming. Analysis of Logistic Regression Model [J]. Computer Aided Engineering. Vol. 14 (2005) No. 3, p. 74-78.

[14]. Wei, W. P., \& Clément, R. A Chinese Conceptualization of Willingness to Communicate in ESL [J]. Language, Culture and Curriculum. Vol. 16 (2003) No. 1, p. 18-38.

[15]. Wu Weiping. An Analysis of the Assessment Tools for Chinese College Students' Intercultural Communicative Competence [J]. Foreign Language Teaching and Research. 2013. No. 4, p. 581-592.

[16]. Wu Xudong. An Investigation of Chinese EFL learners' Self-perceived Communicative Competence and Willingness to Communicate [J]. Modern Foreign Language. 2008. No. 3, p. 280-290.

[17]. Xie Duquan, Guo Yingke. Willingness to Communicate of Chinese College Students: A Structural Equation Model Perspective [J]. Foreign Language and Literature. Vol. 27 (2011) No. 5, p. 116-123.

[18]. . Xu Xiaofeng, Hu Yingen. Farmers' Willingness of Rural Residential Land Exits Based on the Logistic Model [J]. Journal of Anhui Agriculture Science. 2012. No. 31, p. 15542-15545.

[19]. Yi Danhui, He Zheng. Logistic Model and its application [J]. Statistics and Decision. 2003. No. 3, p. 26-28.

[20]. Yin Xuemei, Wu Zhuang. Review of Researches on WTC over Twenty Years [J]. Journal of Xiangtan University (Philosophy and Social Sciences). Vol. 32 (2008) No. 5, p. 154-156. 